\title{
Loss of Empathy in Medical Training: A Sad Behavioral Learning
}

\author{
Juan Antonio Lugo Machado ${ }^{1 *}$ and Dalia Yocupicio Hernández ${ }^{2}$ \\ ${ }^{1}$ Department of Otolaryngolgoy, Centro Médico Nacional del Noroeste, México \\ ${ }^{2}$ University of Sonora, Campus Cajeme, Cd Obregón, Sonora
}

*Corresponding author: Lugo Machado Juan Antonio, Surgeon Specialist in Otorhinolaryngology, Sub specialist in Pediatric Otolaryngology, Assigned Physician of Otolaryngology, National Medical Center of the Northwest, IMSS, Cd. Obregón, Sonora, Mexico.

Received Date: December 17, 2018

Published Date: January 03, 2019

\section{Summary}

Empathy is a very important competence in health professionals, when working with human beings who are in a situation of vulnerability. Technological advances have caused a depersonalization of human relationships and with it a significant erosion of empathy [1,2]. We cannot deny the importance of technological progress, but it has also brought a loss and loss of empathy between health professionals and patients [3,4]. It is necessary to understand this phenomenon and work on it to maintain it, promote it and learn.

\section{Introduction}

Empathy, from the Greek empathies, means knowing how to appreciate the feelings of another. The term empathy was introduced in 1909 by the English psychologist Edward Bradner Titchener, as a translation of the German word einfühlung.

The German word was used to describe the feelings of those who observed a work of art. Titchener wanted, then, to imply that empathy was the attempt to better understand another human being as a result of his contemplation.

It was Southard, in 1918, who first incorporated empathy in the doctor-patient relationship, as a facilitator of diagnosis and therapy [5-7]. Empathy constitutes a bridge between evidencebased medicine and patient-centered medicine: a practical way to incorporate technical progress and translate it into effective patient care.

It is evident that empathy facilitates the work of the doctor to take better care of the patient, interpersonal communication between relatives and other physicians involved in the care process, it is essential that this is an objective to be achieved and taught by future doctors. These reflections are an introduction to a subject whose study and improvement is both necessary and exciting.

There are also those who consider empathy as part of the personality of the individual, something that can be transformed; consequently, it may decline during the process of medical training or it may be improved through well-directed educational activities and there is no shortage of those who affirm that it is very difficult to teach or direct the learning of empathy [8].

The level of empathy can change, and in this case, it deteriorates. Intervening in this process would involve more than teaching new things - "teaching empathy" - in avoiding its attrition and loss [9].

\section{Developing}

Medicine is a profession at the service of the human being. Cultivating human values in general, and developing interpersonal skills and empathy, in particular, are fundamental elements to properly exercise the medical profession, there are times of rapid technological progress, in parallel, such a level of depersonalization in the medical relationship had never been reached patient.

Some authors study empathy -considered in the context of medical education and care for the sick- from the predominantly cognitive aspect, which includes understanding the patient's experiences and concerns as well as the ability to communicate with them. It would be, in some way, how to approach the way of seeing the world that the other has, understand their perspective. From the educational point of view, the cognitive aspect of empathy becomes suggestive, because it seems possible to teach and learn it, to help, diminish or alleviate pain and suffering in the patient.

No one doubts the importance of the knowledge and skills that a health professional should have regarding the subject matter, however, develop, maintain and promote the ability of empathy [10-12], it is necessary to establish a good medical relationship patient and interaction with other health professionals. It seems that in practice these issues are not subject to effective attention in the years of academic preparation.

Halpern points out that empathy approaches the patient's doctor who, in turn, manages to better expose their complaints and 
concerns, facilitating diagnosis and treatment. Through empathy, the autonomy and safety of the patient are also strengthened, contributing to their recovery.

The empathy involves the behavior of the doctor and his attitude when facing the thoughts and feelings of the patient, as well as the way of communicating, which implies cordiality, affection, sensitivity. It is evident that if empathy facilitates the work of the doctor to take better care of the patient, this is an objective to be reached and taught by the future doctors.

The so-called erosion of empathy in health professionals, during the graduation course - a fact that the literature points out with worrying insistence - is a reality [13].

Studies cited from the 1960s to the end of the twentieth century in the United Kingdom and the United States of America consistently find low levels of empathy in health workers.

Different authors such as Hojat et al. [14], Hojat et al. [15,16], Shapiro [17], have found findings of impaired empathy and this has generated concern among educators in the health professions not only in terms of preventing deterioration but as to how to maintain empathy among the students.

Some studies suggest that a drastic transformation occurs in the medical student during his training process [18] in the first years, most of them overflow with enthusiasm and idealism for being a doctor, they are sensitive to the suffering of the patient, over the years, idealism seems to be forgotten and a process of "dehumanization" begins, in which the patient it happens to occupy a secondary role in medical practice [19].

The strong influence that the current model of medical training has on this dehumanization process cannot be denied. The technical-medical information is so great that there is hardly time to address the doctor-patient relationship. This metamorphosis (true disproportion) has been described as a traumatic loss of humanization [20] Therefore, it is necessary to think about a rehumanization process in which empathy in future doctors can be protected and improved. The benefit of knowing how to intervene as soon as possible the sooner the better in this dimension of medical education is evident. It is convenient to comment that the aspects that integrate the behavior of the human being can be modeled and, consequently, feasible to be taught.

Irving and Dickson study empathy as an attitude that contemplates behavioral ability along with the cognitive and affective dimension of empathy. Do not ignore its emotional component, which is related to the ability to feel the experiences and feelings of another. A spontaneous feeling of identification with the sufferer arises, facilitated by emotion. In the case of the student, this perspective is revealed with great clarity. There are few studies that address the evaluation of empathy.

The culture installed in many medical schools suggests maintaining emotional distance from the patient, as if that favored the professional attitude, enough time is dedicated to discuss clinical cases, but it is not often that empathic development among physicians is discussed and their attention to the patient and family, naturally, all this contributes negatively to the development of empathy in the students.

When reflecting on the training process in light of the results obtained and the references of the literature, we observed some factors that could be involved in the erosion of empathy: the lack of adequate examples by the trainers; great amount of technical information to be transmitted with the consequent limitation of time to address the humanistic issues that delineate the doctorpatient relationship; the tension that arises between the ideals of the student and the daily clinical practice in which ethical doubt arises and the emotional overload that derives from contact with suffering.

The objectives are clear, but there are missing structures that are capable of measuring the results, we know what we want to teach, but we cannot evaluate how it is taught and, above all, if it is learned. Some of the instruments to evaluate empathy are the following: Interpersonal Reactivity Index developed by Davis, The Hogan Empathy Scale and the Emotional Empathy of Mehrabian and Epstein [21]. Other evaluation methods have been developed for nurses, such as the Empathy Construct Rating Scale, The Empathy Understanding of Interpersonal Processes Scale, The Empathy Subtest of the Relation Inventory and The Empathy Test.

In this way, educating emotions is an important task to promote empathy and ethical attitudes as a whole. In today's universe, emotions are the main actors in the education scene; educate, therefore, will have to contemplate emotions, never ignore them, and learn to take advantage of them; place them in their true place, facilitating the catharsis and the free flow of them. Sharing emotions or protecting them in open discussions opens paths for a true affective reconstruction that current culture imposes.

Working with emotions to educate them involves a serious educational process in which they must, initially, identify and make themselves explicit; then evaluate its correct used to promote the doctor-patient relationship in the various clinical situations, and as an effective aid to keep the focus of the medical action on its true objective: the benefit of the patient.

\section{Conclusion}

Empathy is essential in the interaction between people, human beings are a social being, therefore requires constant communication with people of the same species. It is evident the erosion of the empathy of the health professional, very well documented is this phenomenon [22].

It is easy to see in the academic environment an increasingly determined search to develop resources that effectively help in the emotional and affective formation of students, a path that certainly tunes in with the promotion of empathy.

We should ask ourselves if the interventions in the educational process should not be directed, rather than teaching something new (to grow in empathy), to prevent its loss and motivate its development. 
The concept of empathy in students of health sciences should be examined in more detail to establish exactly what is changing when the empathy scores of students begin to decrease.

The benefit of knowing how to intervene as soon as possible - the sooner the better - in this dimension of medical education is evident. It is convenient to comment that the aspects that integrate the behavior of the human being can be modeled and, consequently, feasible to be taught.

The importance of the development of empathy as an aspect of emotional competence seems to be a necessary factor that will train us more humane health professionals [23,24].

\section{Acknowledgement}

None.

\section{Conflict of Interest}

No conflict of interest.

\section{References}

1. Moreto G, González-Blasco P, Pessini L, Craice-de Benedetto MA (2014) La erosión de la empatía en estudiantes de Medicina: reporte de un estudio realizado en una universidad en São Paulo, Brasil. Aten Fam 21(1): 16-19.

2. Halpern J (2001) From Detached Concern to Empathy: Humanizing Medical Practice, Oxford University Press, UK.

3. M.H. Davis (1994) Empathy: A Social Psychological Approach, Brown and Benchmark Publishers, USA.

4. P Irving, D Dickson (2004) Empathy: towards a conceptual framework for health professionals Int J Health Care Qual Assur Inc Leadersh Health Serv 17 (4-5): 212-220.

5. EL La Monica, D K Carew, AE Winder, A M Bernazza-Hasse, K H Blanchard (1976) Empathy training as the major thrust of a staff development program. Nurs Res 25: 447-451.

6. WG Kirk, AH Thomas (1982) A brief in-service training strategy to increase levels of empathy of psychiatric nursing personnel J Psychiatr Treat Eval 4: 177-179.

7. JM Layton (1979) The use of modeling to teach empathy to nursing students. Res Nurs Health 2 (4): 163-176.

8. HK Silver, AD Glicken (1990) Medical student abuse: Incidence, severity, and significance JAMA 263(4): 527-532.
9. Graziela Moreto, Pablo González-Blasco, María Auxiliadora Craice-de Benedetto (2014) Reflexiones sobre la enseñanza de la empatía y la educación médica, Atención Familiar 21(3): 94-97.

10. M Hojat, S Mangione, TJ Nasca, Rattner S, Erdmann JB et al. (2004) An empirical study of decline in empathy in medical school. Med Educ 38(9): 934-941.

11. G Moreto, DB Bariani, TRP Pinheiro, R Altisent, PG Blasco (2008) Una Nueva Metodología Docente en Bioetica: Experiencias con la aplicación del Portafolio a Estudiantes de Medicina en Brasil Persona y Bioética 12.2 (31): 133-144.

12. SA La Rocco (2010) Assisting nursing students to develop empathy using a writing assignment. Nurse Educator 35(1): 10-11.

13. U. Forest-Streit (1982) Differences in empathy: a preliminary analysis mJ Med Educ 57: 65-67.

14. D Chen, R Lew, W Hershman, J Orlander (2007) A cross-sectional measurement of medical student empathy. J Gen Intern Med 22(10): 1434-1438.

15. Hojat M (2007) Empathy in patient care. Antecedents development measurement and outcomes, Springer, UK.

16. M Hojat, M Vergare, K Maxwell, G Brainard, S Herrine, et al. (2009) The Devil is in the Third Year: A Longitudinal Study of Erosion of Empathy in Medical School Acad Med 84(9): 1182-1191.

17. J. Shapiro (2008) Walking a mile in their patients' shoes: empathy and othering in medical students' education. Philosophy Ethics and Humanities in Medicine 3 (10): 1-11.

18. MT Edwards, CN Zimet (1976) Problems and concerns among medical students J Med Educ 51: 619-625.

19. M.D. Karr (1994) Acting in medical practice Lancet. 344: 1436.

20. J Kay (1990) Traumatic deidealization and future of medicine JAMA, 263(4): 572-573.

21. AP Goldstein, A Goedhart (1973) The use of structured learning for empathy enhancement in paraprofessional psychotherapists. J Community Psychol 1(2): 168-173.

22. H Spiro (2009) The Practice of Empathy Academic Medicine 84 (9): 1177-1179.

23. SA La Rocco (2010) Assisting nursing students to develop empathy using a writing assignment. Nurse Educator 35(1): 10-11.

24.J Shapiro (2008) Walking a mile in their patients' shoes: empathy and othering in medical students' education. Philosophy Ethics and Humanities in Medicine 3 (10): 1-11. 